Çukurova Üniversitesi Mühendislik Mimarlık Fakültesi Dergisi, 33(4), ss. 203-212, Aralık 2018

\title{
Saklı Markov Modeli Kullanılarak İstanbul'daki Üniversite Öğrencilerinin GSM Operatör Tercihlerini Etkileyen Faktörlerin Analizi
}

\author{
Osman AYAZ ${ }^{1}$, Selçuk ALP*1 \\ ${ }^{1}$ Yıldız Teknik Üniversitesi, Makine Fakültesi, Endüstri Mühendisliği Bölümü, İstanbul
}

Geliş tarihi: 21.02.2018～Kabul tarihi: 25.12.2018

$\ddot{\mathbf{O z}}$

Markov Zinciri modeli pazarlama, eğitim, finans ve imalat gibi birçok alanda kullanılmaktadır. Saklı Markov modelleri ise Markov zincirleri bazı özellikler eklenerek oluşturulmuştur. Bu çalışmada, İstanbul'da eğitim gören üniversite öğrencilerinin GSM operatör tercihlerini etkileyen faktörler ile ilgili bir uygulama yapılmıştır. Saklı Markov Modeli ile öğrencilerin kullandıkları GSM operatörlerini ve bu operatörleri tercih etme nedenleri tahmin edilmiştir. Tahminler sonucunda, tercih edilecek GSM operatörleri sırasıly Turkcell $\% 37,10$, Türk Telekom $\% 31,78$ ve Vodafone $\% 31,12$ olarak bulunmuştur. Elde edilen bulgulara göre bu GSM operatörlerinin tercih sebepleri Turkcell için kapsama gücü, Türk Telekom ve Vodafone için ise fiyat uygunluğu olduğu belirlenmiştir.

Anahtar Kelimeler: Markov zincirleri, Saklı markov modelleri, Marka tercihleri

\section{Analysis of GSM Operator Preference of University Students in İstanbul By Using Hidden Markov Model}

\begin{abstract}
Markov Chain uses in many areas such as marketing, education, finance and manufacturing. Hidden Markov models were created by adding some features to Markov chains. In this study, an application was made about the factors affecting the GSM operator preferences of university students studying in Istanbul. Using the Markov Model, why students prefer for the GSM operators and reason of these choosing of operators were predicted. As a result of the prediction, GSM operators to be preferred were $37.10 \%$, Türk Telekom 31.78\% and Vodafone 31.12\% respectively. According to the obtained evidence, the reasons behind choosing these brands are determined as network coverage for Turkcell and price eligibility for Türk Telekom and Vodafone.
\end{abstract}

Keywords: Markov chain, Hidden markov models, Brand preference

*Sorumlu yazar (Corresponding author): Selçuk ALP, alp@yildiz.edu.tr 


\section{GíRiș}

Günümüzde cep telefonu ve GSM (Global System for Mobil Communication) sektörleri sürekli gelişme gösteren sektörler arasında yer almaktadır. $\mathrm{Bu}$ sektörlerin ülkemizdeki durumları incelendiğinde, halen insanların büyük bir kısmının cep telefonunu aktif bir şekilde kullandığı görülmektedir. Bu durumda GSM operatörlerinin yeni cep telefonu sahibi olacak kişileri abone yapmaya dönük kampanyaların yanı sıra daha büyük bir potansiyele sahip olan ve hâlihazırda cep telefonu kullanan fakat diğer GSM operatörlerini tercih etmiş bulunan aboneleri kendi abonesi yapmaya yönelik kampanyalar üretmeye çalışmaktadırlar. GSM operatörleri uyguladıkları bu kampanyalarla hem abone sayısını arttırmaya hem de abonelerinin diğer operatörlere geçmelerini engellemeye çalışmaktadırlar.

Ülke nüfusumuzun büyük bir kısmını gençler oluşturduğu ve aynı zamanda bu genç kesimin teknolojideki gelişmeleri de daha yakından takip ettiği için üniversite öğrencileri, GSM operatörleri için önemli bir pazar payını abone kaynağını oluşturmaktadır. $\mathrm{Bu}$ çalışmada üniversite öğrencilerinin GSM operatör tercih sıraları ve tercihlerinin altında yatan nedenlerin Saklı Markov Modeli ile belirlenmesi amaçlanmıştır.

\section{MATERYAL VE METOT}

\subsection{Markov Süreci ve Markov Zinciri}

Markov süreci, şu anda meydana gelen bir olayın gelecekteki durumu hakkında olasıliklı bilgiler edinmeyi sağlayan bir yöntemdir. Markov analizinde önceki durumlardan bağımsız olarak, yalnızca mevcut duruma bağlı olan sürecin, nasıl gelişeceğini içeren olasılıkları bulunduran bir özelliği bulunmaktadır [1]. Süreçlerin çoğu uygulamada bu tanıma uymakta ve dolayısıyla da bu süreçlere Markov analizi olasılık modeli uygulanabilmektedir [2]. Markov süreci uygulamalarında, optimal bir sonuca ulaşmak yerine karar vermeye yardımcı olabilecek olas 11 kl $1_{1}$ bilgiler sağlama amacı güdülür [3].
Dizi kümesindeki $\mathrm{n}$ sayıda zaman noktasının herhangi bir $t_{1}<t_{2} \ldots<t_{n}$ kümesi için, $X_{t}$ 'nin $X_{t_{1}}, X_{t_{2}}, \ldots, X_{t_{n}}$ 'nin verilen değerlerine göre koşullu dağılımı yalnızca $X_{t_{n-1}}$ 'in değerine ( $X^{\prime}$ in bir önceki zamandaki değeri) bağlı ise $\left\{X_{t} \in T\right\}$ sürecine Markov Süreci denir. Söz konusu bu durum, matematiksel olarak $P\left(X_{t_{n}}=X_{n} \mid X_{t_{1}}=X_{1}, \ldots ., X_{t_{t-1}}=X_{n-1}\right) P\left(X_{t_{n}}=X_{n} \mid X_{t_{n-1}}=X_{n-1}\right)$ şeklinde ifade edilmektedir $[4,5]$.

Bir Markov sürecinde, sürecin durumunun belirlenmesi koşuluyla sürecin belli olan bu durumdan sonraki ve önceki durumlarının birbirinden bağımsız olması özelliğine Markov özelliği denir [6,7].

Bir Markov süreci, kapsadığı olası durumlar kümesinin sonlu olması, durumların başlangıç olasılıklarının bilinmesi, durumlar arası durağan geçiş olasılıklarının varlığı ve Markov özelliğini taşıması durumunda Markov Zinciri adını almaktadır $[2,8]$.

Markov süreçlerinin, birçok farklı alanda uygulamalarına rastlamak mümkündür. Markov süreçleri, biyoloji, fizik, meteoroloji, üretim, astronomi, kimya ve benzeri fen bilimlerin yanında, ekonomi, finans, eğitim, pazarlama, hukuk, sağlık hizmetleri ve işletme gibi sosyal bilimlerin özel konularında da uygulama olanağı bulmuştur.

\subsection{Saklı Markov Modeli}

Markov zinciri modellerinde sistemin, bir durumdan diğer duruma geçişi söz konusudur. Sistemin bulunabileceği bu durumlar ve durumlar arası geçişler açık bir şekilde gözlemlenebilir durumda ise Markov zinciri söz konusudur. Saklı Markov Modelinde ise durumlar dışarıdan doğrudan gözlemlenemez, yalnızca her bir durumdan meydana gelen gözlem çıktıları gözlemlenebilir. Gözlem çıktılarının bir araya gelmesi ile gözlem dizisi meydana gelmektedir. Saklı Markov Modelinde gözlem dizisinin altında yatan durum dizisinin bilinmemesi, söz konusu 
modellerin "Saklı" olarak ifade edilmesine neden olmaktadır. Ayrıca Saklı Markov Modelinde sistemde meydana gelen gözlemlerden her biri zamandan bağımsızdır ve mevcut durumun her bir olaya ilişkin olasılığı, dağılım değerine bağlı olarak ortaya çıkmaktadır [9].

Saklı Markov Modelinin gözlemlenebilir Markov sürecinden farkı, sistemin herhangi bir anında hangi durumda olduğunun bilinememesi, ancak sistem herhangi bir durumda iken bu durumun tetiklediği gözlemin ortaya konulabilmesidir $[10,11]$.

Saklı Markov Modeli ile ilgili olarak 1940’lı yıllardan itibaren teorik olarak çalışılmaya başlanmış fakat model uygulama alanında yaygınlaşamamıştır. Model, 1960 ve 1970'li y1llarda Baum ve Petrie [12], Baum ve Eagon [13], Baum ve arkadaşları [14] ve Baum [15] tarafından geliştirilmiştir. Son yıllarda özellikle bilgisayar sistemlerinin önemli düzeyde gelişmesi sonucunda uygulama alanları oldukça yaygınlaşmıştır. Saklı Markov Modeli, birbirinden farklı birçok alanda kullanılmıştır (Çizelge 1).

Çizelge 1. Saklı markov modeli kullanılarak gerçekleştirilen bazı çalışmalar

\begin{tabular}{|l|l|}
\hline Konu & Çalışmalar \\
\hline Biyoloji & $\begin{array}{l}\text { Guoliang ve Xia [16], Krogh ve } \\
\text { arkadaşları [17], Yin ve Wang } \\
\text { [18], Felsenstein ve Churchill } \\
\text { [19], Krogh ve arkadaşları [20] }\end{array}$ \\
\hline $\begin{array}{l}\text { Deprem } \\
\text { Tehlikesi }\end{array}$ & Can ve arkadaşları [21] \\
\hline Ekomoni & $\begin{array}{l}\text { Büyüktatlı [3], Can ve Öz [9], } \\
\text { Emam ve Aaghaie [22], Öz [23] }\end{array}$ \\
\hline $\begin{array}{l}\text { Hava } \\
\text { Durumu }\end{array}$ & $\begin{array}{l}\text { Yaman [24], Lambert ve } \\
\text { arkadaşları [25] }\end{array}$ \\
\hline $\begin{array}{l}\text { İnsan } \\
\text { Davranışları } \\
\text { Tanıma }\end{array}$ & $\begin{array}{l}\text { Rabiner [5], Haberdar [10], } \\
\text { Argunşah ve Çetin [26], Tunca } \\
\text { Hanilçi ve Ertaş [29], Uslu [30] }\end{array}$ \\
\hline $\begin{array}{l}\text { Müşteri } \\
\text { İlişkileri } \\
\text { Yönetimi }\end{array}$ & $\begin{array}{l}\text { Emam ve Aaghaie [22], Netzer } \\
\text { ve arkadaşları [31], Can ve Öz } \\
\text { [34] }\end{array}$ \\
\hline
\end{tabular}

\subsection{Saklı Markov Modeli Varsayımları}

Matematiksel ve hesaplamaya dayalı işlemlerde kolaylık sağlaması açısından Saklı Markov Modeli teorisinde Markov, durağanlık ve çıktı bağımsızlık varsayımlarını kullanılmaktadır.

\section{1) Markov Varsayımı:}

Saklı Markov Modelinde geçiş olasılıkları Eşitlik 1 ile gibi tanımlanır.

$a_{i j}=P\left[q_{t}=S_{j} \mid q_{t-1}=S_{i}\right]$

Burada gelecek durumun yalnızca şimdiki duruma bağlı olduğu varsayılmaktadır. Bu durumda model birinci derece Saklı Markov Modeli olmaktadır. Gelecek durum geçmişteki $k$. duruma dayanıyorsa, bu durumda model, $k$. derece Saklı Markov Modeli olarak ifade edilir. $k$. derece Saklı Markov Modelleri için geçiş olasılıkları Eşitlik 2 ile tanımlanır [5].

$$
\begin{aligned}
& a_{i_{1} i_{2} \ldots i_{k} j}=P\left[q_{t+1}=S_{j} \mid q_{t}=S_{i_{1}}, q_{t-1}=S_{i_{2}}, \ldots, q_{t-k+a}=S_{i_{k}}\right] \\
& \left(1 \leq i_{1}, i_{2}, \ldots, i_{k}, j \leq N\right)
\end{aligned}
$$

Yüksek dereceli Saklı Markov Modeli oldukça karmaşık bir yapıya sahip olduğu için uygulamalarda birinci derece Saklı Markov Modeli yaygın bir şekilde kullanılmaktadır.

\section{2) Dură̆anlık Varsayımı:}

Durağanlık varsayımında geçiş olasılıklarının geçerli durumdan bağımsız oldukları kabul edilmektedir. Bu varsayım Eşitlik 3 ile tanımlanır.

$$
\begin{aligned}
& P\left[q_{t_{1}+1}=S_{j} \mid q_{t_{1}}=S_{i}\right]=P\left[q_{t_{2}+1}=S_{j} \mid q_{t_{2}}=S_{i}\right] \\
& \forall t_{1} \text { ve } t_{2}
\end{aligned}
$$

\section{3) Çıktı Bă̆ımsızlık Varsayımı:}

Çıktı bağımsızlık varsayımı ise var olan, geçerli gözlemin (çıktının) önceki gözlemlerden istatiksel olarak bağımsız olması gerektiğini belirtmektedir. Çıktı bağımsızlık varsayımı, $O=O_{1}, O_{2}, \ldots, O_{3}$ olarak 
ifade edilen gözlem serisi ele alınarak formüle edilebilir. Saklı Markov Modeli $\lambda$ için çıktı bağımsızlık varsayımına göre Eşitlik 4 ile tanımlanır.

$$
P\left[O \mid q_{1}, q_{2}, \ldots, q_{T}, \lambda\right]=\prod_{t=1}^{T} P\left(o_{t} \mid q_{t}, \lambda\right)
$$

$\mathrm{Bu}$ varsayımın geçerliliği, diğer iki varsayıma göre çok sınırlıdır. Bazı durumlarda bu varsayım yeterince uygun olmayabilir. Böylece Saklı Markov Modellerinin kuvvetli ve zayıf yönleri ortaya çıkmakatdır [32].

\subsection{Saklı Markov Modelinin Özellikleri}

i) $N$, sistem içindeki durumların sayısını ifade etmektedir. Durumlar saklı olsalar da, genellikle durumlar kümesine $\left(s=\left\{s_{1}, s_{2}, \ldots, s_{N}\right\}\right)$ ilişkin bazı belirgin fiziksel anlamlar bulunmaktadır. Genel olarak, durumlar kendi içlerinde, herhangi bir durumdan diğer durumlara ulaşılabilecek biçimde bağlantılıdır.

ii) $M$, her bir duruma ait ayrık gözlem sembollerinin sayısını ifade etmektedir. Gözlemler sürekli ise, $M$ sonsuzdur. Gözlem sembolleri $\left(v=\left\{v_{1}, v_{2}, \ldots, v_{M}\right\}\right)$, modellenen sistemin fiziksel çıktısına karşılık gelmektedir.

iii) Herhangi bir durumdan diğer durumlara tek bir adımda geçiş olasılıkları standart olasılık kurallarına Eşitlik 5 ve Eşitlik 6 uymalıdır.

$a_{i j} \geq 0 \quad i=1, . ., N j=1, . ., N$

$\sum_{j=1}^{N} a_{i j}=1 \quad i=1, . ., N$

iv) $j$ durumundaki gözlem sembolü olasılığı dağılımı $B=\left\{b_{j}(k)\right\}$ olarak gösterilir ve Eşitlik 7'deki gibi tanımlanmaktadır.

$$
\begin{aligned}
& b_{j}(k)=P\left[v_{k} \text { at } t \mid q_{t}=S_{i}\right] \\
& i=1, . ., N j=1, . ., N
\end{aligned}
$$

Ayrıca, $b_{j}(k)$ için aşağıdaki verilen stokastik kısıtlar sağlanmalıdır (Eşitlik 8 ve 9).

$b_{i j}(k) \geq 0 \quad i=1, . ., N j=1, . ., N$

$\sum_{k=1}^{M} b_{j}(k)=1 \quad i=1, . ., N$

v) Başlangıç durum dağılımı $\pi=\left\{\pi_{i}\right\}$ olarak gösterilmekte ve Eşitlik 10'daki gibi tanımlanmaktadır.

$\pi_{i}=P\left[q_{1}=S_{i}\right] \quad i=1, . ., N$

$N, M, A, B$ ve $\pi$ 'nin uygun değerleri için (her bir $O_{t}$ gözlemi $V_{t}$ sembollerinden biri ve $T$ dizideki gözlemlerin sayısı olmak üzere) Saklı Markov Modeli, $O=O_{1}, O_{2}, \ldots, O_{3}$ gibi bir gözlem dizisini verecek bir üreteç olarak kullanılabilir [23, 32].

\subsection{Saklı Markov Modelinin Özellikleri Üç Temel Problemi ve Çözüm Algoritmaları}

Uygulama alanlarında Saklı Markov Modelini kullanabilmek için literatürde "Saklı Markov Modelinin Üç Temel Problemi” olarak ifade edilen üç problemin çözülmesi gerekmektedir.

Birbirine rakip iki model arasından seçim yapılması istenildiğinde, 1. problemin çözümü gözlemlere en uygun olan modeli seçme olanağı verecektir. Optimal durum dizilerinin bulunmas1 ya da her bir durumun ortalama istatistiklerinin elde edilmesi gibi işlemler için 2. problemin çözümü kullanılır. 3. problem olan Öğrenme problemi, model parametrelerinin, gözlemlenen verilere optimal olarak uyarlanmasina ve bu sayede en iyi modelin yaratılmasına olanak tanımakta olduğundan Saklı Markov Modeli ile ilgili bir çok uygulama için önem taşımaktadır.

Saklı Markov Modelinin üç temel problemi için yaygın bir şekilde kullanılan algoritmalar aşağıda verilmiştir. 
Birinci Problem: Illeri-Yön/Geri-Yön Algoritması

Birinci problemin çözümü için İleri-Yön (Forward) ve Geri-Yön (Backward) algoritmaları kullanılmaktadır. Her iki algoritma ile hesaplanan $P(\mathrm{O} \mid \lambda)$ olasılıkları aynı sonucu vermektedir [9]. İleri-Yön Algoritması gözlemlenen durumların verilen bir modele göre baştan sona doğru olan gerçekleşme olasılıklarını hesaplanmaktadır. GeriYön algoritması ise model tam ters yönde çalışarak aynı olasılıkları hesaplamaktadır.

İleri-Yön algoritması gözlemleri, birbirinin peşi sira zincirleme bir şekilde ele almaktadır. $t$ zamanda gözlemleri ele aldıktan sonra koşullu durumların dağılımını tekrarlı olarak hesaplar [3].

İleri-Yön değişkeni $\alpha_{t}(i)=P\left(O_{1} O_{2} \ldots \mathrm{O}_{t}, q_{t}=S_{i} \mid \lambda\right)$ biçiminde tanımlanır ve $t$ anında $S_{i}$ durumundaki sistemin $O_{1} O_{2} \ldots \mathrm{O}_{t}$ kısmi gözlem dizisinin olasılığ şeklinde ifade edilir. İleri-Yön algoritması 3 adımdan oluşmaktadır. $\mathrm{Bu}$ adımlar aşağıdaki şekilde verilebilir [9].

i) Başlangıç anında tüm durumlar için $O_{1}$ gözleminin meydana gelme olasılığı hesaplanarak algoritma başlatılır Eşitlik 11 ve 12).

$$
\begin{aligned}
& \alpha_{1}(i)=P\left(O_{1}, q_{1}=S_{i} \mid \lambda\right) \\
& =P\left(O_{1} \mid q_{1}=S_{i}, \lambda\right) P\left(q_{1}=S_{i} \mid \lambda\right) \\
& \alpha_{1}(i)=\pi_{i} b_{i}\left(O_{1}\right), \quad t=1, i=1, \ldots, N
\end{aligned}
$$

ii) Herhangi bir $t$ zamanında tüm $D_{i}$ durumlarından $t+1$ zamanında $D_{j}$ durumuna geçiş $\alpha_{t+1}(j)$ değişkeni ile hesaplanır (Eşitlik 13).

$$
\begin{aligned}
& \alpha_{i+1}(j)=\left[\sum_{i=1}^{N} \alpha_{t}(i) a_{i j}\right] b_{j}\left(O_{i+1}\right), \\
& t=1, \ldots, T-1, \quad j=1, \ldots, N
\end{aligned}
$$

iii) Son adımda istenilen $P(O \mid \lambda)$ olasılığı İleriYön değişkenlerinin $\quad\left(\alpha_{T}(i)=P\left(O_{1} O_{2} \ldots O_{T}, q_{T}=S_{i} \mid \lambda\right)\right)$ toplamı olarak verilir (Eşitlik 14).

$$
P(O \mid \lambda)=\sum_{i=1}^{N} P\left(O, q_{t}=S_{i} \mid \lambda\right)=\sum_{i=1}^{N} \alpha_{T}(i)
$$

Geri-Yön algoritması değerlendirme probleminin çözümünde kullanılan ikinci bir yoldur. Geri-Yön olasılık değişkeni $\beta_{T}(i)$ aşağıdaki gibi tanımlanarak başlanmaktadır (Eşitlik 15).

$$
\begin{aligned}
& \beta_{T}(i)=P=\left[O_{i+1}, O_{i+2}, \ldots, O_{T} \mid s_{i}, \lambda\right] \\
& t=1, \ldots, T s_{i} \in S
\end{aligned}
$$

i) Başlangıç anında tüm $i$ 'ler için $\beta_{T}(i)$ değerleri 1 olarak kabul edilir (Eşitlik 16).

$$
\beta_{T}(i) \quad i=1, \ldots, N
$$

ii) Yineleme (Eşitlik 19):

$$
\begin{aligned}
& \beta_{t}(i)=\sum_{j=1}^{N} a_{i j} b_{j}\left(O_{t+1}\right) \\
& i=1, \ldots, N t=T-1, T-2, \ldots, 1
\end{aligned}
$$

Bir dizi gözlem sırası göz önüne alındığında SM Modelinin gözlem sırasının en iyi açıklaması bulunmaktadır. Diğer bir ifade ile $P(O \mid \lambda)^{\text {'y1 }}$ maksimum kılan $\lambda$ değerinin bulunması ya da $\lambda^{*}=\arg \max _{\lambda} P(O \mid \lambda)$ farklı olarak belirtmek gerekirse, problem belirli bir gözlem sırası için en olası Saklı Markov Modeli parametrelerini tahmin etmektir [23, 33].

\section{İkinci problem: Viterbi Algoritması}

Viterbi algoritması, çözümleme problemi olarak da tanımlanmaktadır. $\mathrm{Bu}$ algoritma, gözlenen sembollerin altında gerçekleşen optimum durum dizisini ortaya çıkarmayı amaçlamaktadır. Optimum olma tanımı, durumların her biri için tek tek ya da bir gözlem dizisinin tamamı için yapilabilir. Tek tek durumlar üzerinden optimizasyon mantık dışı sonuçlar doğurabileceği ve aynı zamanda karmaşık olduğu için tercih edilmez [30].

Bazı uygulamalar için ardışık gözlemler içerisinde yer alan ardışık durumların tahminin gerekliliği 
saptanmıştır. Viterbi algoritması, $P^{*}$ olasılığının maksimizasyonunu sağlayacak en iyi durum ardışıklığının bulunmasında kullanılır.

Viterbi Algoritması orijinalinde karmaşık çözümlemeli kodların analizi için planlanmıştır. Saklı Markov Modelinde verilen gözlem ardışıkları $O=\left\{o_{1}, o_{2}, \ldots, o_{T}\right\}$ için en olası durum ardışıklığını $Q^{*}=\left\{q_{1}^{*}, q_{2}^{*}, \ldots, q_{T}^{*}\right\} \quad$ bulmak için kullanılmaktadır. Önceki tanımlamada da olduğu gibi, fonksiyon maksimum $Z$ değerinin $y$ argümanına karşılık geldiğini göstermektedir (Eşitlik 18).

$\arg \max \{z\}$

Viterbi algoritması hem $P(Q \mid 0)$ nokta olasılığı hem de $P(Q \mid 0)$ koşullu olasılığı eş zamanlı olarak maksimize etmektedir [3].

Viterbi algoritmasının işlem adımları aşağıda verilmişstir.

i) Her bir durumun başlangıç olasılık değeri ile birinci gözlemin olasılık değeri çarpılır. $\mathrm{Bu}$ durumda maksimum argüman belirleyen $\psi_{i}(i)$ değişkeni sıfır değerini alır (Eşitlik 19 ve 20).

$\delta_{1}(i)=\pi_{i} b_{i}\left(O_{1}\right), i=1,2, \ldots, N$

$\psi_{1}(i)=0, i=1,2, \ldots, N$

ii) Ayrı ayrı tüm durumlar için elde edilen $\delta_{t-1}(i)$ değerleri geçiş olasılıkları ile çarpılır. Daha sonra bu çarpım değerleri içindeki maksimum değer ile mevcut durumdaki gözlem olasılığı çarpılır. $\mathrm{Bu}$ işlem sonucunda maksimum değere sahip olan durum, $\psi_{1}(j)$ değişkenine atanır (Eşitlik 21).

$$
\begin{aligned}
& \delta_{t}(i)=\max _{i=1}^{N}\left[\delta_{t-1}(i) a_{i j}\right] b_{j}\left(O_{t}\right), \\
& t=2, \ldots, T, j=1,2, \ldots, N \\
& \psi_{t}(i)=\underset{i=1}{\arg \max }\left[\delta_{t-1}(i) a_{i j}\right], \\
& t=2, \ldots, T, j=1,2, \ldots, N
\end{aligned}
$$

iii) İkinci adımdaki son gözlem için hesaplanan $\delta_{T}(i)$ değerleri içinden maksimum olanı $P^{*}$ 'a atanır. $q_{T}^{*}$ ise seçilmiş olan maksimum $\delta_{T}(i)$ 'nin hangi durumdan geldiğini belirlemektedir. $\mathrm{Bu}$ sonuç, son gözlem için optimum durumu verir (Eşitlik 23 ve 24).

$$
\begin{aligned}
& P^{*}=\max _{i=1}^{N}\left[\delta_{T}(i)\right] \\
& q_{T}^{*}=\underset{i=1}{\arg \max }\left[\delta_{T}(i)\right]
\end{aligned}
$$

iv) Son adımda, son gözlemden ilk gözleme doğru geri yönde ilerlenir. Her bir geri yönlü adımda $q_{t}^{*}=\psi_{t+1}\left(q_{t+1}^{*}\right)$ ifadesi ile bir sonraki adımda elde edilmiş olan optimum sonucun hangi durumdan geldiği bulunur. $\mathrm{Bu}$ işlem $T=1$ yani başlangıç anına kadar devam eder. $\mathrm{Bu}$ adım sonunda $q_{t}^{*}$ değişkeninin aldığı durumlar dizisi, optimum durum dizisini oluşturur (Eşitlik 25) [9].

$q_{T}^{*}=\psi_{t+1}\left(q_{t+1}^{*}\right), T=T-1, T-2, \ldots, 1$

Viterbi algoritmasında yer alan işlemler ileri-yön algoritmasındaki işlemlere benzemektedir. İki algoritma arasında fark sadece toplam yerine maksimum değerin alınmasıdır. Viterbi algoritması ile en yüksek olasılığı veren yol üzerinden $P(O \mid \lambda)$ olasılığı elde edilir. $\mathrm{Bu}$ olasılık değeri $\left(P^{*}\right)$ sinıflamada da kullanılabilir [27].

\section{Üçüncü Problem: Baum-Welch Algoritması}

Baum-Welch algoritması için ileri/geri yön algoritması ifadesi de kullanılmaktadır. $\mathrm{Bu}$ algoritma önceki bilgi için seçilen ilk değerler $P, \phi, \pi$ parametrelerinin kullanımında başlar. Sonra mevcut modelin kullanımı, bu alıştırma seti için tüm yollar $P, \phi, \pi$ 'nin yeni olasılık değerleri kullanılmak suretiyle göz önünde tutulmalıdır. Mevcut modeldeki parametrelerdeki değişiklikler devam ettiği sürece işlem tekrar edilir. Baum-Welch algoritmasının işlem adımları aşağıda verilmiştir. 
i) $\mathrm{t}=1$ zamanında $s_{i}$ durumu için beklenilen sıklıktaki ilk durum dağıtımının tahmini $\bar{\pi}=\gamma_{1}(i)$ şeklinde hesaplanır.

ii) $\bar{p}_{i j}$ ve $\bar{\phi}_{j}(k)$ tahminlerinin ilk tanımlamaları bulunur.

iii) Mevcut model $\lambda=(P, \phi, \pi) ; \quad \bar{p}_{i j}$ ve $\bar{\phi}_{j}(k)$ değerlerinin toplamıdır. Güncellenmiş modelin kullanımında yeni iterasyonlar $\bar{\lambda}=(\bar{P}, \bar{\phi}, \bar{\pi})$ şeklinde kullanılır. Yeni model ile eski model birbirlerine yaklaşıncaya kadar bu işleme devam edilir.

iv) $\delta$ önceden tanımlanmış başlangıç değeri ise, $P[O \mid \bar{\lambda}]-P[O \mid \lambda]<\delta$ olduğunda, işlem durur [3].

\section{UYGULAMA}

\subsection{Araștırma Konusu}

$\mathrm{Bu}$ çalışmada, üniversite öğrencilerinin GSM operatör tercihleri ve bu tercihlerin altında yatan nedenlerin Saklı Markov Modeli ile belirlenmesi amaçlanmıştır. Veri toplama yöntemi olarak anket yöntemi seçilmiştir.

Uygulamada Saklı Markov Modelinin üç temel probleminden ilk ikisi kullanılmıștır. Üçüncü temel model parametrelerinin yeniden yapılandırılmasının üzerine kuruludur. Model parametrelerinin yeniden yapılandırılması çalışma kapsamı içinde olmadığı için uygulamaya dâhil edilmemiştir.

GSM operatör marka tercihleri ve tercih nedenlerinin belirlenmesine yönelik olarak çalışmanın hedefini İstanbul'daki üniversite öğrencileri oluşturmaktadır.

Çalışmanın verileri anket yöntemi ile basit tesadüfi örnekleme yöntemi kullanılarak elde edilmiştir. Ankette yer alan soru ve cevapların hazırlanmasinda anketlerden elde edilen cevaplar ve literatür taramasında elde edilen bilgilerden yararlanılmıştır. Ankette dört tane kategori sorusu bulunmaktadır. Birinci soru, şu anda kullanılan GSM operatör markasının seçimi, ikinci soru, kullanılan bu markanın tercih nedeninin seçimidir. Üçüncü soru, bir önceki kullanılan GSM operatör markasının seçimi, dördüncü soru ise bir önceki kullanılan GSM operatör markasının tercih nedeninin seçimidir.

Türkiye'de bulunan tüm üniversite öğrencilerine anketi ulaştırmanın zorluğundan dolayı çalışmanın ana kitlesini İstanbul'daki üniversitelerde okuyan öğrenciler oluşturmuştur. İstanbul'daki üniversitelerde 2016-2017 yılında eğitim gören öğrenci sayısı YÖK verilerine göre 1.2 milyon'dur. Ana kitle hacmi 1.2 milyon olduğundan çalışmanın \%97 güven düzeyinde olması için örneklem hacminin en az 1066 olması gerekmektedir.

Elde edilen 2004 adet anketin bir bölümü (96 adedi) eksik bilgi ya da çelişkili ifadeler içermesi nedeniyle işlem dışı bırakılmıştır. Geriye kalan 1908 adet anketle analizler gerçekleştirilmiştir.

Üniversite öğrencilerinin GSM operatör tercihlerinin ve tercih nedenlerinin Saklı Markov Modeli ile tahmin edilebilmesi için Saklı Markov Modelini oluşturan parametrelerin belirlenmesi gerekir.

Belirli bir zamanda herhangi bir GSM operatör markasının tercih edilmesinin altında yatan neden Saklı Markov Modelinin "durum'u" olarak alınmıştır. $\left\{q_{t}=D_{i}\right\}$.

GSM operatör marka tercih nedenleri, anketlerde yer alan açık uçlu sorulara verilen cevaplar değerlendirilerek belirlenmiştir. $\mathrm{Bu}$ sayede elde edilen tercih nedenleri literatürden elde edilen nedenler ile karşılaştırılmış ve uygulama için 7 temel tercih nedeni belirlenmiştir.

GSM operatörü marka tercih nedenleri için bir önceki ve şu anki tercih nedenleri kullanılarak geçiş olasılıkları matrisi kurulmuştur. Geçiş olasılıkları matrisi satır ve sütunları $D=\left\{D_{1}, D_{2}, D_{3}, D_{4}, D_{5}, D_{6}, D_{7}\right\}$ şeklinde (Çizelge 2) ifade edilen bir önceki kullanılan GSM operatör 
tercih nedeninden şu anda kullanılan GSM operatör tercih nedenine geçiş olasılıklarını (Çizelge 3) $\left\{A=\left\{a_{i j}\right\}\right\}$ içermektedir.

Çizelge 2. SM modeli için saklı durumlar

\begin{tabular}{|c|l|}
\hline Sembol & \multicolumn{1}{|c|}{ Saklı Durumlar } \\
\hline$D_{1}$ & $\begin{array}{l}\text { Uygun fiyatlı tarifeler (Tüm } \\
\text { müşterilerine) }\end{array}$ \\
\hline$D_{2}$ & $\begin{array}{l}\text { Numara taşıyanlara özel uygun fiyatlı } \\
\text { tarifeler }\end{array}$ \\
\hline$D_{3}$ & $\begin{array}{l}\text { Gençlere sunulan hizmetler } \\
\text { (Gnctrkcll, Freezone, Selfy) }\end{array}$ \\
\hline$D_{4}$ & İnternet hızı \\
\hline$D_{5}$ & Şebeke kapsama alanının genişliği \\
\hline$D_{6}$ & Marka imajı \\
\hline$D_{7}$ & Müşteri hizmetlerinin kalitesi \\
\hline
\end{tabular}

Çizelge 3. Geçiş olasıllkları matrisi

\begin{tabular}{|c|c|c|c|c|c|c|c|}
\hline$a_{i j}$ & $D_{1}$ & $D_{2}$ & $D_{3}$ & $D_{4}$ & $D_{5}$ & $D_{6}$ & $D_{7}$ \\
\hline$D_{1}$ & 0,29 & 0,16 & 0,10 & 0,08 & 0,21 & 0,08 & 0,08 \\
\hline$D_{2}$ & 0,18 & 0,45 & 0,05 & 0,09 & 0,09 & 0,09 & 0,05 \\
\hline$D_{3}$ & 0,26 & 0,16 & 0,05 & 0,11 & 0,21 & 0,16 & 0,05 \\
\hline$D_{4}$ & 0,29 & 0,18 & 0,24 & 0,18 & 0,12 & 0,00 & 0,00 \\
\hline$D_{5}$ & 0,26 & 0,10 & 0,13 & 0,00 & 0,39 & 0,06 & 0,06 \\
\hline$D_{6}$ & 0,42 & 0,13 & 0,16 & 0,00 & 0,03 & 0,23 & 0,03 \\
\hline$D_{7}$ & 0,18 & 0,09 & 0,36 & 0,09 & 0,09 & 0,00 & 0,18 \\
\hline
\end{tabular}

Ankette yer alan bir önceki durumda kullanılan GSM operatör marka (Çizelge 4) tercihi $V_{k}$ ve şu anda kullanılan GSM operatör marka tercihi $V_{k+1}$ sorularına verilen yanıtlar Saklı Markov Modelinin "gözlemleri” olarak alınmıştır.

Çizelge 4. Markaları ifade eden gözlemler

\begin{tabular}{|c|l|}
\hline Sembol & Gözlemler \\
\hline$V_{1}$ & Turkcell \\
\hline$V_{2}$ & Türk Telekom \\
\hline$V_{3}$ & Vodafone \\
\hline
\end{tabular}

GSM operatör tercihleri, tercih nedenleri ile birleştirildiğinde gözlem olasılıkları matrisi $\left\{B=\left\{b_{j}(k)\right\}\right\}$ oluşturulmaktadır. Bu matrise göre herhangi bir durumda iken GSM operatör markalarının tercih olasılıkları verilmiștir. (8) ve (9) ifadeleri ile açıklanan gözlem olasılıkları matrisi anket cevaplarına göre hazırlanmıştır.
Başlangıç anında GSM operatör tercih nedenlerinin birbirlerine göre bir önceliği olmamasından dolayı başlangıç durum olasılıkları eşit olarak alınmıştır (Çizelge 5).

Çizelge 5. Gözlem olasılıkları matrisi

\begin{tabular}{|c|c|c|c|}
\hline & $V_{1}$ & $V_{2}$ & $V_{3}$ \\
\hline$D_{1}$ & 0,0341 & 0,6383 & 0,3276 \\
\hline$D_{2}$ & 0,0580 & 0,4646 & 0,4774 \\
\hline$D_{3}$ & 0,2752 & 0,2111 & 0,5137 \\
\hline$D_{4}$ & 0,7334 & 0,100 & 0,1666 \\
\hline$D_{5}$ & 0,8276 & 0,0217 & 0,1507 \\
\hline$D_{6}$ & 0,6788 & 0,1315 & 0,1897 \\
\hline$D_{7}$ & 0,4736 & 0,1843 & 0,3421 \\
\hline
\end{tabular}

Saklı Markov Modelinin birinci problemi kullanılarak $\lambda$ modeli için kullanılan $P(O \mid \lambda)$ değerleri, bir önceki ve şu anki GSM operatör tercihlerinden sonraki tercih edilecek markaya ilişkin olasılıkları ifade etmektedir. Burada yer alan O değeri GSM operatör markalarının her birini ayrı ayrı göstermek için kullanılır. $P(O \mid \lambda)$ olasılığının hesaplanmasında (11), (13) ve (14) ifadeleri ile verilen İleri-Yön algoritması kullanılmıştır.

Bir önceki ve şu anki kullanılan GSM operatör tercihlerinden sonraki tercihin olasılığ belirlendiğinde bu tercihin altında yatan nedenin ne olacağının bulunması Saklı Markov Modelinin İkinci Problemi kullanılarak hesaplanmıştır. $V_{l}, V_{2}$, $V_{3}$ gözlemleri için saklı durumların bulunması işlemleri Viterbi algoritması kullanılarak gerçekleştirilmiştir.

\subsection{Sonuç ve Öneriler}

İleri Yön ve Viterbi Algoritmalarıyla ile elde edilen sonuçlar Çizelge 6 ve Çizelge 7 'de yer almaktadır.

Çizelge 6. Marka tercih olasılıkları

\begin{tabular}{|l|c|}
\hline Marka & Gözlemler \\
\hline Turkcell & 37,10 \\
\hline Türk Telekom & 31,78 \\
\hline Vodafone & 31,12 \\
\hline
\end{tabular}


Çizelge 6'ya göre tahminler sonucunda en yüksek olasılıkla tercih edilecek GSM operatör markası Turkcell $(\% 37,10)$ bulunmuştur. Turkcell'in ardından Türk Telekom $(\% 31,78)$ ve Vodafone $(\% 31,12)$ gelmiştir.

Çizelge 7. Marka tercihleri için saklı durumlar

\begin{tabular}{|l|c|}
\hline Marka & Saklı Durum \\
\hline Turkcell & $D_{5}$ \\
\hline Türk Telekom & $D_{1}$ \\
\hline Vodafone & $D_{1}$ \\
\hline
\end{tabular}

Çizelge 7'ye göre markaların tercih sebeplerinin Turkcell için şebeke kapsama alanının genişliği, Türk Telekom ve Vodafone markaları için ise uygun fiyatlı tarifeler (tüm müşterilerine) olduğu tahmin edilmiştir. $\mathrm{Bu}$ durum GSM operatörleri açısından değerlendirildiğinde şebeke kapsama alanının genişliği ve uygun fiyatlı tarifeler (tüm müşterilerine) gelecekte oluşacak marka tercihlerinde en etkili nedenler olduğu belirlenmiştir.

Kullanılan verileri İstanbul'daki üniversite öğrencilerine yönelik olup 1908 tane anket cevaplandırılmıştır. Çalışmanın anlam düzeyinin yükseltilebilmesi için \%97 yerine \%99 tercih edilebilir. Anket sayısını arttırarak tahminlerin daha güvenilir olması sağlanabilir.

Çalışma yalnızca üniversite öğrencilerine uygulanmak yerine GSM abonelerinin tümüne yapılabilir. Böyle bir çalışmada ankette yer alabilecek çeşitli demografik özelliklere (yaş, cinsiyet ve öğrenim durumları vb.) göre farklı sonuçlar elde edilebilir.

\section{KAYNAKLAR}

1. Rüzgar, N.S., 2003. Bir İşletmenin Ödemeler Dengesinin Markov Süreçleri Yardımıyla Analizi, DEÜ SBE Dergisi, 5(1), 164-179.

2. Çöloğlu, M.İ., 2006. Bir Makinanın Güvenilirliğinin Tehlike Fonksiyonu ve Markov Zinciri ile Analizi, Yayınlanmamış Yüksek Lisans Tezi, Osmangazi Üniversitesi FBE, Eskişehir.

3. Büyüktatlı, F., 2013. Şirketlerdeki Erken Uyarı Göstergeleri ile SM Modeli Üzerine Bir
Uygulama, Yayınlanmamış Yüksek Lisans Tezi, Akdeniz Üniversitesi SBE, Antalya.

4. Gürbüz, H., Köse, T., 2002. Şüpheli Alacak Zararlarının Büyüklerinin Markov Zinciri Teorisi ile Hesaplanmas1, Afyon Kocatepe Üniversitesi İIBF Dergisi, 4(2), 49-66.

5. Rabiner, L.R., 1989. A Turorial on Hidden Markov Models and Selected Applications in Speech Recognition, Proceeding of the IEE, 77(2), 257-286.

6. Günay, F., 2011. İki Siralı Markov Zincirleri, Yayınlanmamış Yüksek Lisans Tezi, Fırat Üniversitesi FBE, Elazı̆̆.

7. Pfeifer, P.E., Carraway, R.L., 2000. Modelling Customer Relationships as Markov Chains, Jounal of Interactive Marketing, 14(2), 43-55.

8. Aytemiz, T., Şengönül, A., 2004. Markov Zincirlerinin Ekonomik Bir Probleme Uygulanması: Perakende Alış verişlerde Bireysel Olarak Kullanılan Madeni para Stratejilerinin Karşılaştırmalı Analizi, DEÜ Sosyal Bilimler Dergisi, 6(4), 29-43.

9. Can, T., Öz, E., 2009. SM Modelleri Kullanılarak Türkiye'de Dolar Kurundaki Değişimin Tahmin Edilmesi, İÜ İşletme Fakültesi Dergisi 38, 1-23.

10. Haberdar, H., 2005. SM Model Kullanılarak Görüntüden Gerçek Zamanlı Türk İşaret Dili Tanıma Sistemi, Yayınlanmamış Yüksek Lisans Tezi, YTÜ FBE, İstanbul.

11. Ghahramani, Z., 2001. A Introduction to Hidden Markov Models and Bayesian Networks, A Introduction to Hidden Markov Models and Bayesian Networks, Journal of Pattern Recognition and Artificial Intelligence, 15(1), 9-42.

12. Baum, L.E., Petrie, T., 1966. Statistical Inference for Probabilistic Functions of Finite State Markov Chains, the Annals of Mathematical Statistics, 37(6), 1554-1563.

13. Baum, L.E., Eagon, J.A., 1967. An Inequality with Applications to Statistical Estimation for Probabilistic Functions of a Markov Process and to a Model for Ecology, Bulletin of the American Mathematical Society, 73(3), 360-363.

14. Baum, L.E., Petrie, T., Solues, G., Weis, N., 1970. A Maximization Technique Occurring in the Statistical Analysis of Probabilistic 
Functions of Markov Chains, The Annals of Mathematical Statistics, 41(1),164-171.

15. Baum, L.E., 1972. An Inequality and Associated Maximization Technique in Statistical Estimation for Probabilistic Functions of Markov Processes. In: Oved Shisha, ed. Inequalities III: Proceedings of the Third Symposium on Inequalities. New York: Academic Press, 1-8.

16. Guoliang, F., Xia, X.G., 2003. Wavelet-Based Texture Analysis and Synthesis Using Hidden Markov Models, IEEE Trans. Circ. Syst. I: Fundam. Theory Appl. 50, 106-120.

17. Krogh, A., Larsson, B., von Heijne G., Sonnhammer, E.L.L., 2001. Predicting Transmembrane Protein Topology with a Hidden Markov Model: Application to Complete Genomes, Journal of Molecular Biology 305(3), 567-580.

18. Yin, M.M., Wang, J.T.L., 2001. Effective Hidden Markov Models for Detecting Splicing Junction Sites in DNA Sequences, Information Sciences 139, 139-163.

19. Felsenstein, J., Churchill, G.A., 1996. A Hidden Markov Model Approach to Variation Among Sites in Rate of Evolution, Molecular Biology and Evolution 13(1), 93-104.

20. Krogh, A., Brown, M., Mian K.S., Sjölander, K., Haussler, D., 1994. Hidden Markov Models in Computational Biology Applications to Protein Modeling, Journal of Molecular Biology, 235(5), 1501-1531.

21. Can, C., Ergün, G., Gökçeoğlu, C., 2013. Bilecik Çevresinde Deprem Tehlikesinin SM Modeli ile Tahmini, Türkiye Deprem Mühendisliği ve Sismoloji Konferansı, 25-27 Eylül, Hatay.

22. Emam, S., Asghaie, A., 2011. Introducing Busy Customer Portfolio Using Hidden Markov Model, Iranian Journal of Management Studies, 4(2), 99-119.

23. Öz, E., 2009. İMKB Üzerine SM Modeli ile Bir Tahminleme, Ekonomik Yaklaşım, 20(72), 59-85.

24. Yaman, N., 2014. Modelling Precipitation Data of Certain Regions for Turkey via Hidden Markov Models, Yayınlanmamış Yüksek Lisans Tezi, METU The School of Natural and Applied Sciences, Ankara.
25. Lambert, M.F., Whiting J.P., Metcalfe, A. V., 2003, A Non-Parametric Hidden Markov Model for Climate State Identification, Hydrology and Earth System Sciences 7(5), 652-667.

26. Argunşah, A., Çetin, M., 2010. Saklı Markov Modelleri ve Boyut İndirgemeye Dayalı Bir Beyin-Bilgisayar Arayüzü Algoritması, IEEE 18. Sinyal İşleme ve İletişim Uygulamaları Kurultayı, 22-24 Nisan, Diyarbakır.

27. Tunca, A., 2010. SM Modelleri ve Sürekli Konuşma Tanıma Tekniğiyle Rakam Dizisi Tanıma, Yayınlanmamış Yüksek Lisans Tezi, Osmangazi Üniversitesi FBE, Eskişehir.

28. Cilla, R., Patricio, M.A., Garcia, J., Berlanga, A., Molina, J.M., 2009. Recognizing Human Activities from Sensors Using Hidden Markov Models Constructed by Feature Selection Techniques, Algorithms 2, 282-300.

29. Hanilçi, C., Ertaş, F., 2007. Sürekli Saklı Markov Modelleri ile Metinden Bağımsız Konuşmac1 Tanıma Parametrelerinin İncelenmesi, Uludağ Üniversitesi MühendislikMimarlık Fakültesi Dergisi, 12(1), 109-114.

30. Uslu, E., 2007. Gizli Markov Modeli ile Geniş Sözlüklü Sürekli Konuşma Tanıma, Yayınlanmamış Yüksek Lisans Tezi, YTÜ FBE, İstanbul.

31. Netzer, O., Lattin, J.M., Srinivasan, V., 2008. A Hidden Markov Model of Customer Relationship Dynamics, Marketing Science, 27(2), 183-204.

32. Semerci, Z., 2006. Saklı Markov Modellerinde Üç Temel Problemin İncelenmesi, Yayınlanmamış Yüksek Lisans Tezi, Hacettepe Üniversitesi FBE, Ankara.

33. Ibe, O.C., 2013. Markov Processes For Stochastıc Modeling, $2^{\text {nd }}$ Edition, Elsevier Inc., Lowell, USA.

34. Can, T., Öz, E., 2009. Marka Tercihlerine ve Tercih Nedenlerine Gizli Markov Modelinin Uygulanması, Eskişehir Osmangazi Üniversitesi Sosyal Bilimler Dergisi, 10(2), 167-186. 